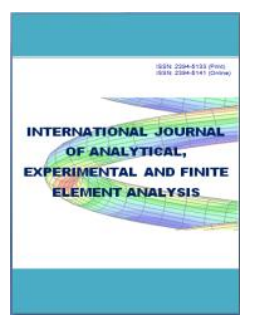

Abdulfatai, A. Faro ${ }^{1}$ ayodejifaro@gmail.com

Kazeem, K, Salam ${ }^{1}$

kaykaysalam@gmail.com

Edith, E. Alagbe ${ }^{2}$

edithalagbe@yahoo.co.uk

${ }^{1}$ Ladoke Akintola University of Technology (LAUTECH), Department of Chemical Engineering, P.M.B. 4000, Ogbomoso. Oyo State. Nigeria.

${ }^{2}$ Convenant University,

Department of Chemical Engineering, KM. 10, Idiroko Road, Canaan Land, Ota, Ogun State.

*Corresponding author

\title{
Design and Analysis of a Vertical Pressure Vessel with Effect of Rotational Velocity on the Stresses and Deformation by using ANSYS
}

Abstract - In this study, the suitability and influence of Rotational Velocity (RV) on the operating conditions of a vertical Pressure Vessel (PV) was investigated. A vertical PV was designed and analyzed with the aid of ANSYS. Effect of eight different parameters on the performance of the designed PV was analyzed. The results obtained from designed PV using Finite Element Analysis (FEA) was validated by comparing it with that obtained from Manually Computed Method (MCM) and Utilization Factor (UF) method. The results of this investigation show that the designed PV was safe within the specified operating condition, the FEA results are more accurate than that of MCM and presence of $\mathrm{RV}$ affected the stress distribution and deformation of the PV.

Index Terms-Vertical pressure vessel, ANSYS.

\section{INTRODUCTION}

Pressure Vessels (PV) are closed container, tanks or pipelines designed to receive and store fluid at a pressure greater than outer ambient pressure condition. PVs are applied for fluid storage in fluid flow related industries such as chemical, petroleum, petrochemical and nuclear industry. PVs are designed to accommodate fluid at high temperature-high pressure and at different fluid characteristics such as volatile, compressible, flammable and radioactive fluids without deviation in its standard operation. The primary consideration in the design of this vessel is safety of the vessel. Physical testing of the properties of PV was discarded because its timing consuming and expensive to practise especially when it is compared to the use of simulation to study how PV will respond to fluid behaviour and final simulation of designed vessel [1].

The use of Computation Fluid Dynamics (CFD) for analyzing mechanical properties of PV has recorded satisfactory results. One of the notable investigations in this field was the work on suitability of PV to accommodate fluid stored by studying its structural and thermal behavior [1]. The design compared the numerical values obtained from ANSYS with analytical values calculated from equations, and comparison of the numerical values with standard values available in the literature. The results obtained show that the simulated values obtained for both the stress induced in the bolt material and Von Misses stress are below the allowable stress threshold and therefore are suitable for storage of fluid under investigation.

Thermal behavior of two different metals was investigated by Satyanarayana and Praveena [2] who analyzed the temperature and heat flux distributions on PV for two different materials (aluminium alloy and steel). Aside the establishment of the accuracy of the model from the percentage error value of $15 \%$, the analysis show that both metals exhibited different behavior at varying temperature but similar trend when 
heat flux of both was considered. Maximum principal and shear stress were the parameters used for the selection of material that used as fuel tank [3]. The results reported from the ANSYS analysis have a deviation of $3.58 \%$ when the maximum principal and shear stress obtained from the software was compared with the one obtained from the MCM.

The behavior of cylindrical PV with the use of hemispherical head type as the end connection in cast iron was analyzed in the work of Wadkar et al. [4]. The results obtained show that the reduced values of equivalent stresses and its distribution are attributed to the use of hemispherical end connection on the cast iron cylindrical PV. Also, the importance of end connection used was demonstrated where the suitability of two different end connections, hemispherical and circular end as part of the component of pressure vessels using the stress distributions were compared [5]. The analysis of Khobragade and Hiwase [5] supported the position of Wadlkar et al.[4] on the lower values recorded for hemispherical end connection when compared with that of flat circular end connection.

It has been established that ANSYS is a tool that can accurately analyze the suitability of material selected as PV and with a low deviation from the standard. Also, the addition of components to PV design change the mechanical properties used for characterizing PV[5]. Therefore, this research work investigated the Vertical Pressure Vessel with Effect of Rotational Velocity on the Stresses and Deformation by using ANSYS.

\section{METHODOLOGY}

\section{A. Material Selection and Input Parameters for Vertical} Pressure Vessel Design

The information regarding the dimension and properties of the pressure vessel used for this simulation was tabulated in Table 1. The choice of information was based on ASME Code Section VIII, Division 1 and complied with specification set by (ASME, 2010). The selection of material is based on the appropriateness of the design requirement. The materials used in the manufacture of the receivers complied with the requirements of the relevant design code[3]. The selection of materials of the shell shall take into account the suitability of the materials with the maximum working pressure and fabrication process. Structural steel was being considered for this investigation and the PV design specification tabulated in table 1 .

TABLE I

INPUT FACTORS FOR PV DESIGN

\begin{tabular}{|c|l|c|}
\hline S/No & \multicolumn{1}{|c|}{ Parameters } & Values \\
\hline 1 & Head Internal Diameter $(\mathrm{mm})$ & 2134 \\
\hline 2 & Head Thickness (mm) & 27 \\
\hline 3 & Head Outer Diameter $(\mathrm{mm})$ & 2188 \\
\hline 4 & Shell Internal Diameter $(\mathrm{mm})$ & 2134 \\
\hline 5 & Shell Outer Diameter $(\mathrm{mm})$ & 2182 \\
\hline 6 & Shell Thickness (mm) & 24 \\
\hline 7 & Length of Shell (mm) & 1076 \\
\hline 8 & Length of Head (mm) & 15 \\
\hline 9 & Internal Pressure(Pi) $(\mathrm{MPa})$ & 200 \\
\hline 10 & Young Modulus (GPa) & 0.30 \\
\hline 11 & Poisson Ratio & 258.4 \\
\hline 12 & Design Pressure(Pd) (Pa) & \\
\hline 13 & Rotational Velocity (rad/s) & 157500 \\
\hline & &
\end{tabular}

\section{B. Finite Element Analysis using the ANSYS Workbench}

The steps adopted using FEA in this investigation are Pre-processing (mesh generation, boundary condition and model display), solution and post-processing respectively.

a. Pre-processing: The vertical PV model was designed with skirt support by selecting the static structural model with parameters input via the engineering data and development of the geometry. The three dimensional solid model of the skirt support and pressure vessel constructed using ANSYS design modular was presented in figure 1a. After the design, two types of meshing were adopted in this research namely meshing by algorithm and meshing by element shape respectively. 
Under the mesh generation, three-dimensional solid model of the skirt support and PV was constructed using ANSYS design modular shown in Figure 1a. Meshing is done for solid model to ensure the optimum mesh size of FEA model for proper convergence and exact numerical results. Meshed model of solid is shown further, and in the meshed model find the total number of elements and total number of nodes as presented in figure $1 \mathrm{~b}$. Meshing was done for solid model to ensure the optimum mesh size of FEA model for proper convergence and exact numerical results.

a

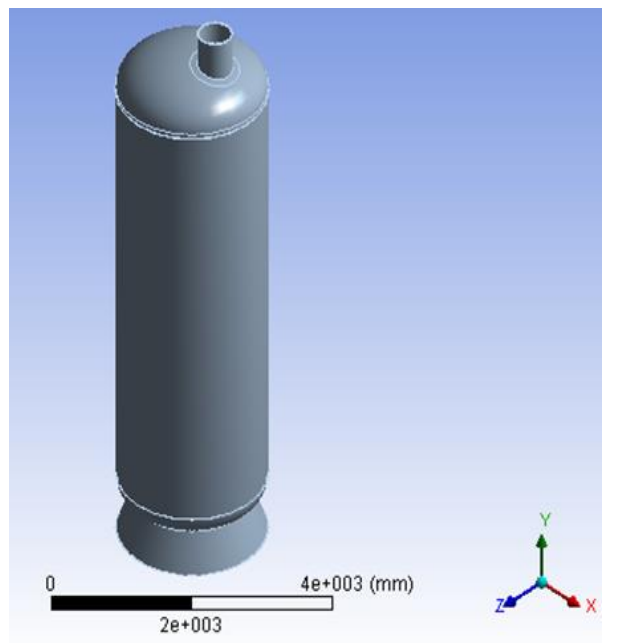

b

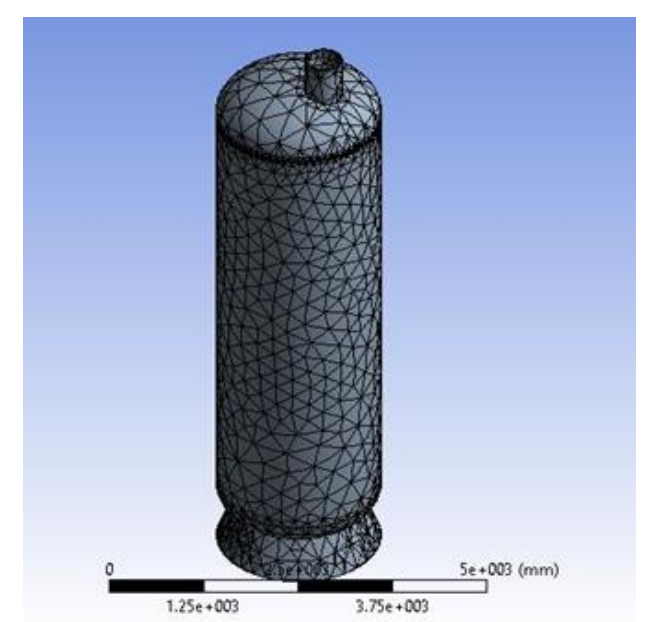

Figure 1. (a) ANSYS Geometry model of the vertical PV and (b) in its meshed form

After completion of the finite element model, boundary conditions and loads are applied. The boundary conditions are the collection of different forces, pressure, supports and any other condition required for complete analysis of PV. Applying condition is one of the most typical processes of analysis. A special care is required while assigning loads and constraints to the elements. After imposing boundary condition on the model, the model was viewed from different angles. Pre-processor offers capabilities of rotating, smoothness, scaling, and regions etc. for efficient model viewing and editing.

b. Solution: The solution phase deals with the solution of the problem according to the problem definition. All the tedious work of formulating and assembling of matrices are done by the computer and finally displacements and stress values are given as output.

c. Postprocessor: It is a powerful user-friendly postprocessing program using interactive colour graphics. It has extensive plotting features for displaying the results obtained from the finite element analysis. The entire range of post-processing options of different types of analysis can be accessed through the command/menu mode thereby giving the user added flexibility convenience. (Kumar, 2016)

At the end of the ANSYS design and modelling, stresses and deflections in the PV walls due to the internal pressure are analyzed. Some of the analyzed variables are the maximum displacement, principal stress and shear stress distribution under the operating pressure and also the effect of rotational velocity on these stresses. The results from the ANSYS analysis was validated by comparison of these results with the results obtained from numerical modelling of PV which was described in section 2.2

\section{Manual Computation Method (MCM)}

The manual computation was developed after it has been established from the material selection and the input parameters for the vessel design that it's a thin-walled cylindrical vessel from the assumption $r / t \geq 10$ and figure 1 was used to explain the direction of stress in the PV. Equations used for the estimation of circumferential and longitudinal stresses, the ellipsoidal head thickness, 
total deformation and the principal stresses are written in equation 1-21 below:

\section{Analysis of a Vertical Pressure Vessel.}

When a thin cylindrical shell is subjected to an internal pressure, it is likely to fail in circumferential and longitudinal stress. Tensile stress acting in a direction tangential to the circumferential is called circumferential or hoop stress. In other words, it is a tensile stress on longitudinal section or on the cylindrical walls. It may fail along the longitudinal section (i.e. circumferentially) splitting the cylinder into two troughs, as shown in Figure 2(a). Tensile stress acting in the direction of the axis is called longitudinal stress. In other words, it is tensile stress acting on the transverse or circumferential section or on the ends of the vessel. It may fail across the transverse section (i.e. longitudinally) splitting the cylinder into two cylindrical shells, as shown in Fig. 2(b) [5].

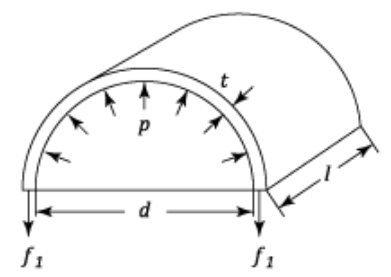

(a)

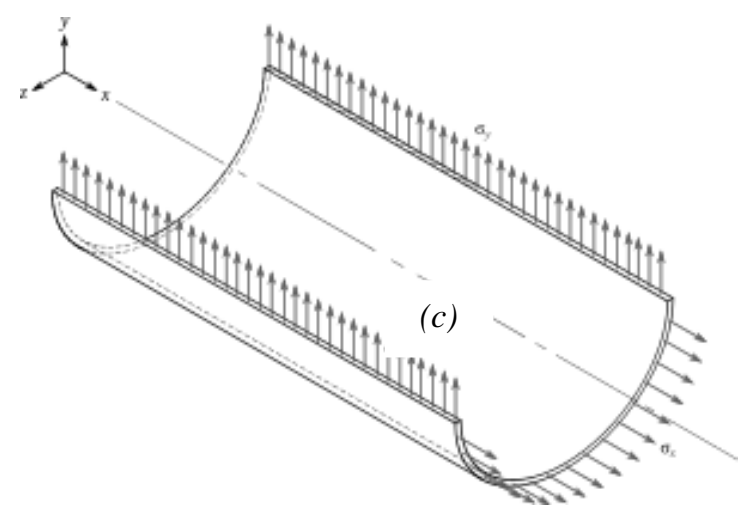

Figure 2: Failure of pressure vessel along longitudinal section and transverse section

For a Thin-walled cylindrical pressure vessel, several assumptions have been made to derive the following equations for circumferential and longitudinal stresses:

- Plane sections remain plane

- $\mathrm{r} / \mathrm{t} \geq 10$ with $t$ being uniform and constant
- Material is linear-elastic, isotropic and homogeneous.

- Stress distributions throughout the wall thickness will not vary

- Weight of the fluid is considered negligible [6].

\section{a. Circumferential Stress}

The circumferential and longitudinal stress of PV were presented in equation 1 and 2 from the research of Wadker, et al.[4].

$$
\delta_{1}=\frac{P d}{2 t}
$$

The external pressure $P_{o}$ and internal pressure $P_{i}$, are expressed as:

$$
\delta_{1}=\frac{\left(P_{i}-P_{t}\right) d}{2 t}
$$

b. Longitudinal Stress

$\delta_{2}=\frac{P_{0} d}{4 t}$

$P_{\mathrm{i}}=$ internal pressure

$\mathrm{d}=$ internal diameter

$\mathrm{t}=$ thickness of the wall

$\delta_{1}$ and $\delta_{2}=$ circumferential and longitudinal stress

c. Calculating the shell thickness

The circumferential and longitudinal joints are estimated using equation 4 and 5 below:

$$
\begin{aligned}
& t_{1}=\frac{P R}{(S E-0.6 P)}+C \cdot A \\
& t_{2}=\frac{P R}{(25 E+0.4 P)}+C \cdot A
\end{aligned}
$$

$t_{1} \& t_{2}=\min$ required vessel thickness for circumferential and longitudinal stresses ( $\mathrm{mm})$

$\mathrm{R}=$ internal radius of vessel, $\mathrm{mm}$

$\mathrm{S}=$ max. Allowable stress, $\mathrm{Pa}$

$\mathrm{E}=$ joint efficiency, $\min$

C. $A=$ corrosion allowance, $\mathrm{mm}$ 
d. Analysis of Ellipsoidal Head thickness

The ellipsoidal head thickness was determined using the formula found in the research of $\mathrm{Li}[7]$

$$
t^{y}=\frac{P_{2} d_{3}}{(2 S E-0.2 P)}
$$

Where $t^{\prime}=$ thickness of Ellipsoidal head, mm; $\mathrm{P}_{1}=$ Design pressure, $\mathrm{Pa} ; \mathrm{d}_{\mathrm{i}}=$ inner diameter, $\mathrm{mm} \mathrm{S}=$ maximum allowable stress, $\mathrm{Pa}$ and $\mathrm{E}=$ Joint Efficiency, $\mathrm{mm}$

Design Pressure $=1.05 *$ maximum working pressure (Internal Pressure, $\mathrm{P}_{\mathrm{i}}$ )

$$
\begin{aligned}
& \mathrm{P}_{1}=1.05 * \mathrm{Pi}=1.05\left(1.5 * 10^{7}\right)=15750000 \mathrm{~Pa} \\
& \delta h=623991666^{\mathrm{Pa} / \mathrm{mm}} \\
& \text { i.e. } \mathrm{Sh}=624 \mathrm{Mpa}
\end{aligned}
$$

For the calculation of total deformation (displacement);

$$
\delta h=\mathrm{eE}
$$

Where $\varepsilon=$ Hoop strain, $\mathrm{mm}$ and $\mathrm{E}=$ Young modulus, $\mathrm{mm}$

e. Analysis of Cylinder

$$
\delta h=\frac{P_{\mathrm{i}}\left(d_{\mathrm{a}}^{2}+d_{\mathrm{s}}^{2}\right)}{\left(d_{\mathrm{a}}^{2}+d_{\mathrm{u}}^{2}\right)}
$$

Where $\delta \mathrm{h}=$ hoops stress, $\mathrm{MPa} ; \mathrm{d}_{\mathrm{o}}=$ outer diameter, $\mathrm{mm}$; $\mathrm{d}_{\mathrm{i}}=$ inner diameter, $\mathrm{mm}$; and $\mathrm{P}_{\mathrm{i}}=$ internal pressure, MPa.

f. Calculation of the pressure vessel rotational velocity

$$
V=\pi r^{2} h
$$

$\mathrm{V}=$ Volume of the vessel; $1.2784 \mathrm{E}+009 \mathrm{~mm}^{3}$

$\mathrm{h}=$ Height of cylindrical container; $6096 \mathrm{~mm}$

Equations 1-12 were implemented using MATLAB 2014b using Table 2 as the constants used for the model. The determined variables were extracted and compared with the results gotten from FEA simulation.
TABLE II

THE INPUT DATA USED FOR NUMERICAL ANALYSIS

\begin{tabular}{|c|l|c|}
\hline S/No & \multicolumn{1}{|c|}{ Variables } & Values \\
\hline 1 & Volume of the Vessel & $1.278 \mathrm{e}^{+009} \mathrm{~mm}^{3}$ \\
\hline 2 & Height of the Cylindrical container & $6096 \mathrm{~mm}$ \\
\hline 3. & Design pressure & $15.75 \mathrm{MPa}$ \\
\hline 4. & Internal pressure & $15 \mathrm{MPa}$ \\
\hline 5. & Young modulus & $200 \mathrm{GPa}$ \\
\hline 6. & Length of Ellipsoidal head. & $1076 \mathrm{~mm}$ \\
\hline 7. & Joint efficiency & 1 \\
\hline
\end{tabular}

g. Validation of ANSYS Model

Two different criteria were selected for the validation of results obtained from ANSYS model such as Utilization Factor (UF) criterion and comparative studies between the Analyzed results from ANSYS and numerical method. The Utilization Factor (UF) criterion was adopted from the research of Askestrand and Gudmestad[8]. The PV fails the UF test if UF value for that parameter is greater than 1 .

$$
U F=\frac{\text { Analysis Result }(A R)}{\text { Design Result }(D R)}
$$

The AR was obtained from the ANSYS model while the DR was obtained from equations 16-17 below:

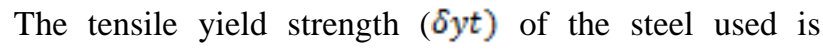
$250 \mathrm{MPa}$

Partial safety factor, $\gamma \mathrm{R}$ for the material is:

$$
\gamma \mathrm{R}=1.5
$$

Allowable stress $(\delta a l l)$ can be estimated using the expression found in the research of Wadler, (2016).

$$
\delta a l l=\frac{d y t}{1.5}
$$

Where $\delta y t=$ Tensile yield strength

The DR was obtained from the expression, $4 * \delta a l l$.

When the numerical analysis and FEA method using ANSYS workbench is completed, the results obtained will be compared and the differences in the results will be established. The comparison will be done for type of stresses distribution and also the displacement. 


\section{RESULTS AND DISCUSSION}

\section{A. Material Property}

The material considered was SA-516 Grade 70, UNS K02700 (Structural steel) with main properties specified in Table 3. Table 3 was generated as output base on the input feed to ANSYS as tabulated in Table 1. Table 3 was presented as it was generated from the Engineering data of the ANSYS Workbench.

\section{TABLE III}

Material Properties (Structural SteEl) ObTained From ANSYS WORKBENCH

\begin{tabular}{|c|c|}
\hline \multicolumn{2}{|l|}{ Structural } \\
\hline Young's Modulus & $2 . e+005$ \\
\hline Thermal Expansion $\left(1 /{ }^{\circ} \mathrm{C}\right)$ & $1.2 \mathrm{e}-005$ \\
\hline Tensile Yield Strength $(\mathrm{Pa})$ & $2.5 \mathrm{e}+008$ \\
\hline Compressive Yield Strength $(\mathrm{Pa})$ & $2.5 e+008$ \\
\hline Bulk Modulus (Pa) & $1.6667 \mathrm{e}+005$ \\
\hline Compressive Ultimate Strength & 0 \\
\hline Specific Heat $\left(\mathrm{mJ} \mathrm{kg}^{-1} \mathrm{C}^{-1)}\right.$ & $4.34 \mathrm{e}+005$ \\
\hline Thermal Conductivity $\left(\mathrm{W} \mathrm{mm}^{-1} \mathrm{C}^{-1}\right)$ & $6.05 \mathrm{e}-002$ \\
\hline Resistivity (ohm mm) & $1.7 \mathrm{e}-004$ \\
\hline \multicolumn{2}{|l|}{ Strain-Life Parameters } \\
\hline Strength Coefficient (MPa) & 920 \\
\hline Strength Exponent & -0.106 \\
\hline Ductility Coefficient & 0.213 \\
\hline Ductility Exponent & -0.47 \\
\hline Cyclic Strength Coefficient (MPa) & 1000 \\
\hline Cyclic Strain Hardening Exponent & 0.2 \\
\hline Relative Permeability & 1000 \\
\hline
\end{tabular}

\section{B. Analysis of PV performance}

Eleven boundary conditions were imposed on the designed PV but effect of only six was presented in Figure 3. The boundary conditions shown are: internal pressure, fixed support, equivalent stress, maximum principal stress, maximum shear stress and total deformation respectively. The remaining five (5) boundary conditions: normal stresses at both $\mathrm{X}$ - and $\mathrm{Y}$ axis, shear stresses at both XY- and YZ- and XZ-planes are shown in Figure A1 in the Appendix.
Figure $3(\mathrm{a} \& \mathrm{~b})$ showed the behavior of PV to fixed internal pressure of $15 \mathrm{mPa}$ and fixed support respectively. In Figure 3b, the support was fixed along Xaxis and was responsible for the symmetry nature of the fluid inside the PV while the figure $3 \mathrm{a}$ show a uniform distribution of the pressure at the inner circumference of the vessel. The behavior PV to Von-misses stress, maximum principal stress, maximum shear stress and maximum deformation distributions varies from each element in the PV to another. Their values are different across the entire PV section as can be seen in Figure 3 (c to f).

\section{Validation of ANSYS Results}

The DR obtained for this PV design was 666. $68 \mathrm{MPa}$ $(4 * 166.8 \mathrm{MPa})$. The UF of both the FEA and MCM results are presented in Table 4. The maximum principal stress design even with a UF of 1.11 for FEA is considered acceptable and the reason for this is careful engineering judgment when reading and evaluating the simulation results. The value of the total stress calculated for points $3.2 \mathrm{~mm}$ to $6.5 \mathrm{~mm}$ from the end showed was 664Mpa which is acceptable. It can be stressed that the stress concentration was only local and the vessel will not sustain any total plastic deformation. However, the vessel should be evaluated according to the protection against local failure procedure.

The acceptance criteria from the UF results show that five (5) of the eight considered parameters stresses were less than or equal to 1 , a trend that was similar to the simulation results of other researchers Askestrand and Gudmestad[8]. The values of UF obtained for both analyses are close to each other and the cross plot of the UF from both the MCM and FEA are plotted in Figure 4. The UF results obtained show that the designed PV can withstand fluid stress without failure by considering the Elastic Stress Analysis [9]. 


\section{Influence of Rotational Velocity on Performance of $P V$}

The FEA has been carried out pressure vessel. In boundary condition, the vessel is supported at the end corners and internal pressure of $15 \mathrm{MPa}$ is applied at the inner surface.

The boundary conditions and design values with directions for the imposed actions were shown in Figure 5. The figure 5a show that the internal pressure was apply to the inner surface of the vessel, the fixed support (B) was fixed in x-direction and accounts for the symmetry

a
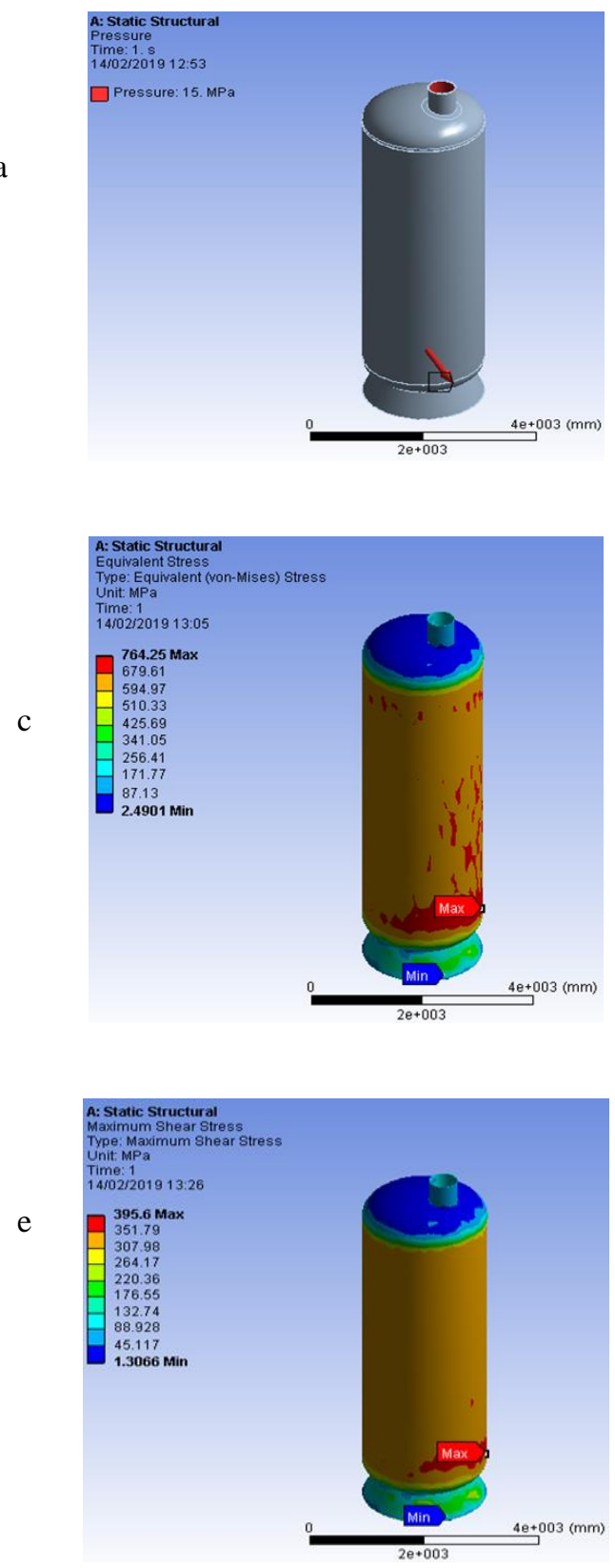

conditions, the standard earth gravity (C) was imposed at normal occurrence and the Rotational velocity (D) effect was checked on the stresses and deformation.

From the above figure 5 (b to $\mathrm{f}$ ) showed that there is increase in all the stresses considered and also the deformation under the application of relative velocity. Von-mises stress distribution throughout the pressure vessel increased under the application of relative velocity. In this condition, the increment in all considered parameters was experienced in the similar investigation conducted[10].

$\mathrm{b}$
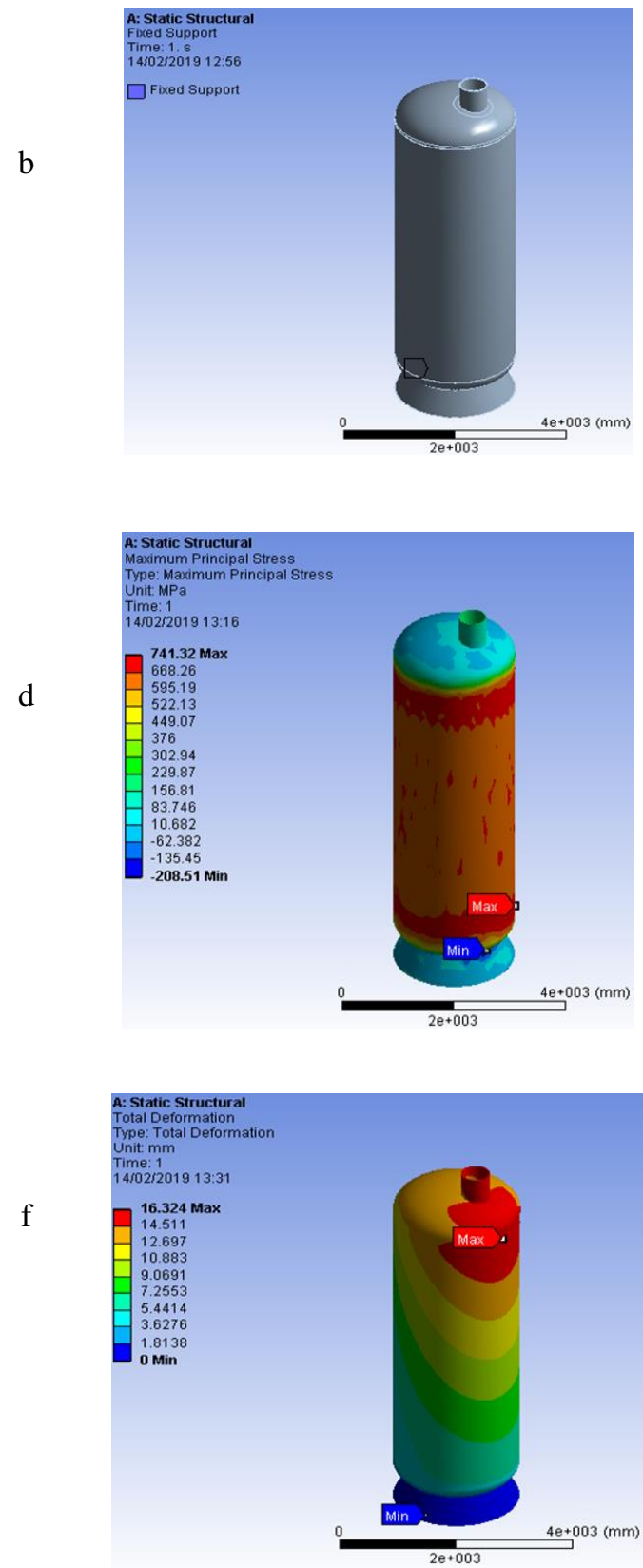

Figure 3. Analysis of PV using different boundary condition 
TABLE IV

THE UF FOR BOTH FEA AND MCM ANALYSIS

\begin{tabular}{|c|c|c|c|c|c|}
\hline S/No & Types of Stress & FEA results & MCM results & UF of FEA & UF of MCM \\
\hline 1 & Max. principal stress (MPa) & 741.32 & 675 & 1.1119578 & 1.01247975 \\
\hline 2 & Max. shear stress (MPa) & 395.6 & 334 & 0.5933881 & 0.50098998 \\
\hline 3 & X-Normal stress (MPa) & 713.84 & 667 & 1.0707386 & 1.00047999 \\
\hline 4 & Y-Normal stress $(\mathrm{MPa})$ & 255.4 & 334 & 0.3830923 & 0.50098998 \\
\hline 5 & XY-Shear Stress (MPa) & 259.36 & 175 & 0.3890322 & 0.26249475 \\
\hline 6 & XZ-Shear Stress(MPa) & 378.89 & 342 & 0.5683236 & 0.51298974 \\
\hline 7 & YZ-Shear Stress (MPa) & 178.85 & 167 & 0.2682696 & 0.25049499 \\
\hline
\end{tabular}

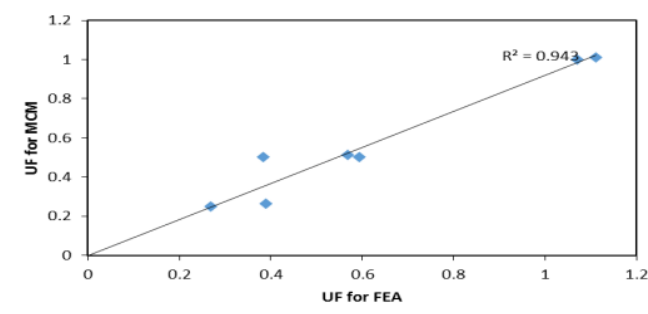

Figure 4. The crossplot of UF obtained for FEA and MCM

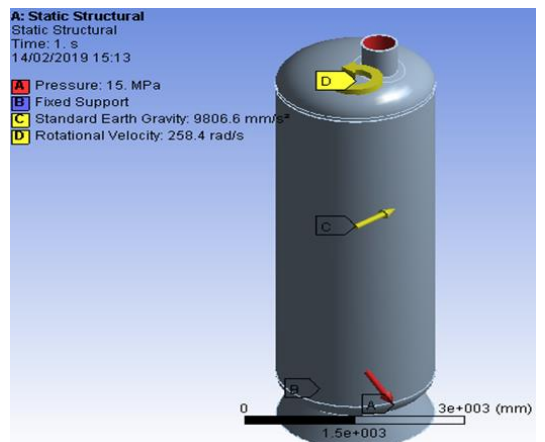

c

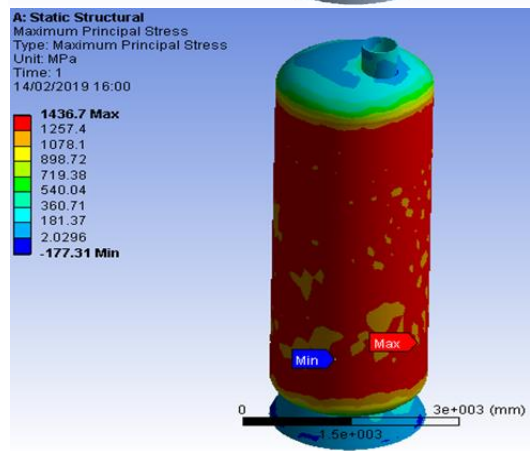

e

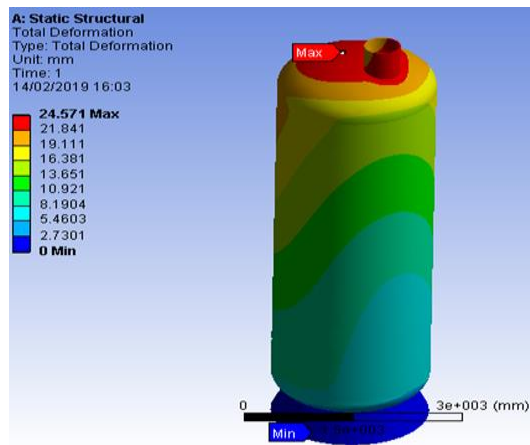

b
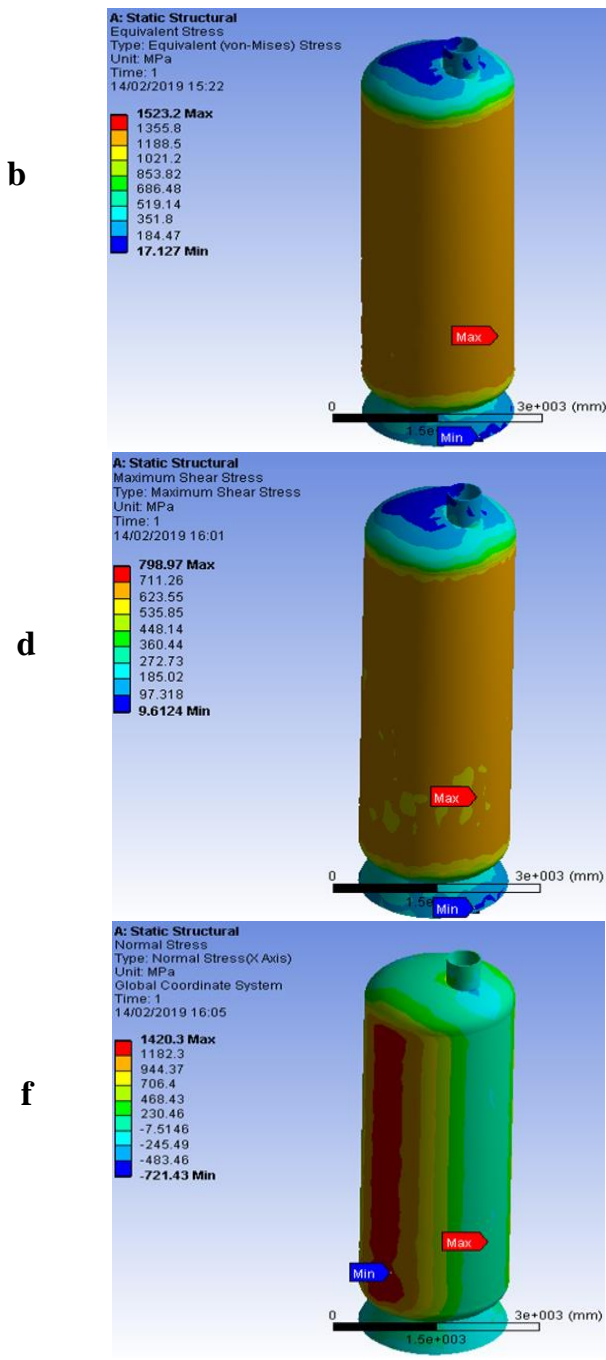

Figure 5. Influence of rotational velocity on the behaviour of PV at different boundary conditions 
In Figure 6 to 8, the results of the effect of RV on maximum principal stress, normal stress in both $\mathrm{X}$ and $\mathrm{Y}$ axis against deformation was presented. The three figures show that there was a linear relationship between deformation and any of the considered parameters analyzed for a case where RV was absent in the PV designed.

However, when influence of RV was considered for the three parameters, it was observed the values of deformation at the three cases were greater than the values of the corresponding case in the absence of RV. Also, the deformation of the three plots initially increased with increase in each of the parameters until a deformation point where the plots drop. The drop in plots was experienced at deformation value of $33.74 \mathrm{~mm}$ for all the three cases considered.

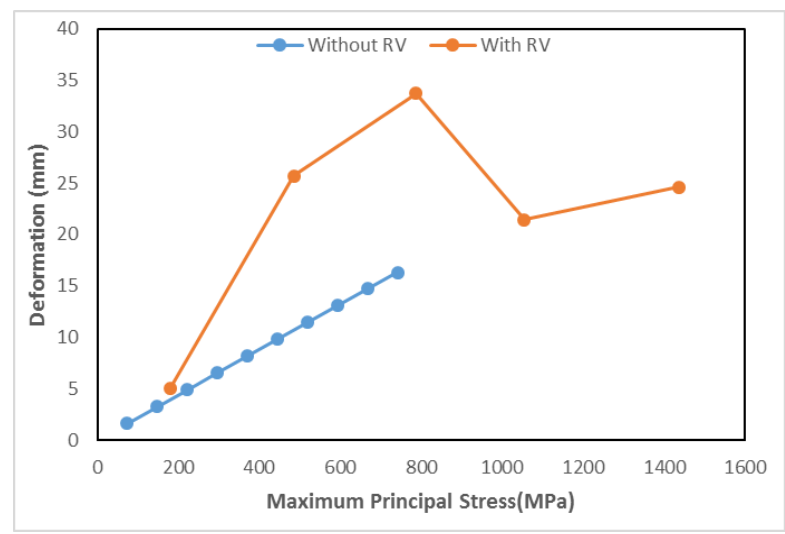

Figure 6. Plot of deformation vs maximum principal stress for both without RV and with RV

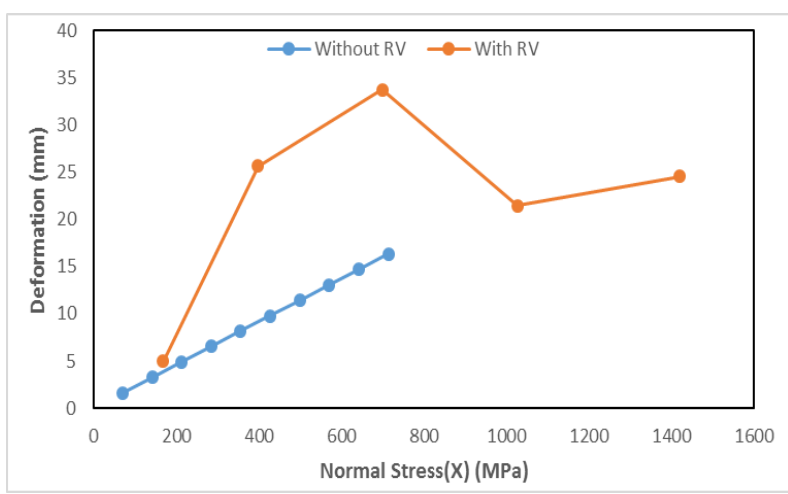

Figure 7. Plot of stress vs deformation for Normal stress(X) or circumferential stress at both without RV and with RV

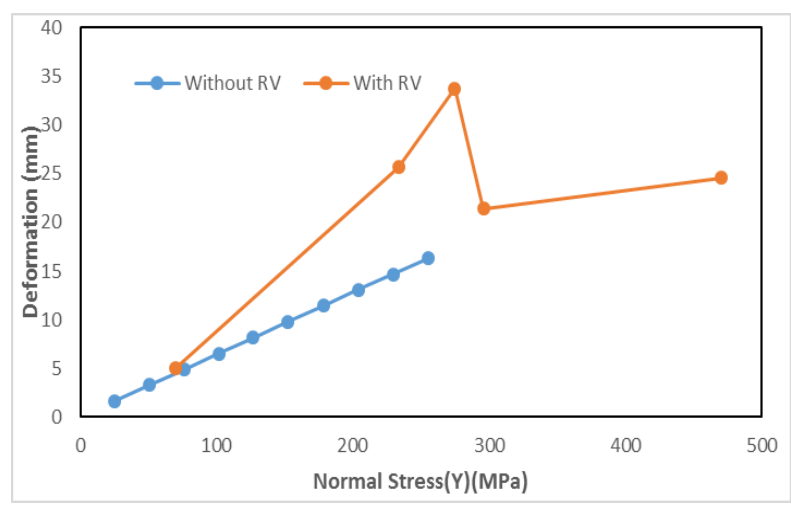

Figure 8. Plot of normal stress vs deformation for longitudinal stress at both without RV and with RV

The influence of the RV on all considered stresses analyzed was presented in Figure 9. The bar chart showed that the value of all stresses where RV was included in the design was greater than the one without RV.

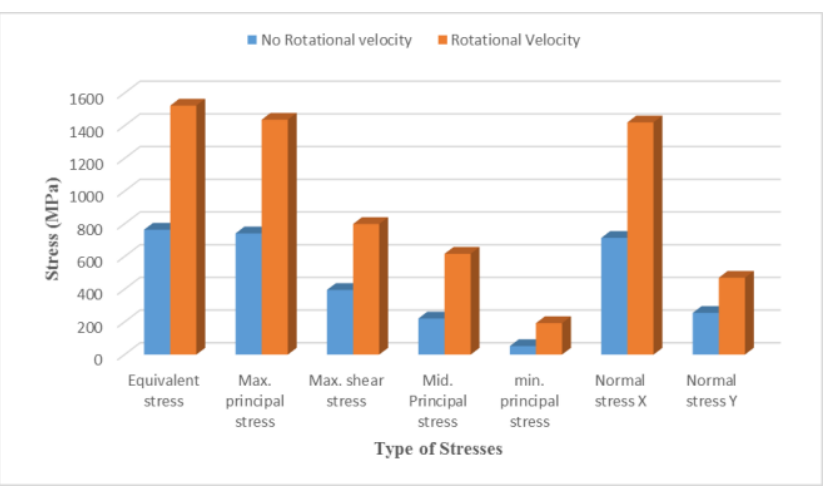

Figure 9. Effect of stress distribution with and with RV in PV design

\section{CONCLUSION}

The following deductions were arrived at during the investigation of the suitability of the designed PV and the influence of $\mathrm{RV}$ on the stress and deformation of designed PV analyzed using ANSYS:

- The influence of RV on the analysed parameters was important to stress distribution for the PV designed in this investigation.

- The boundary conditions imposed on the designed ellipsoidal vertical PV show that this design is safe under the specified operating conditions.

- The values of the FEA results are similar and in the same trend with that of results obtained from MCM which validated the results from FEA. 
- The FEA method is more accurate and flexible when its output was compared to that of MCM.

\section{NOMENCLATURE}

\begin{tabular}{|c|c|}
\hline Abbreviations & Meaning \\
\hline FEA & Finite Element Analysis \\
\hline FEM & Finite Element Method \\
\hline ASME & American Society Of Mechanical Engineers \\
\hline JIS & Japanese Industrial Standard \\
\hline RSM & Reference Stress Method \\
\hline CAD & Computer Aided Design \\
\hline UF & Utilization Factor \\
\hline RV & Relative Velocity \\
\hline $\mathrm{PV}$ & Pressure Vessel \\
\hline MCM & Manually Computed Method \\
\hline \multicolumn{2}{|l|}{ Characters } \\
\hline$\delta^{1}$ & Maximum principal stress \\
\hline$\delta^{2}$ & Middle principal stress \\
\hline$\delta^{3}$ & Minimum principal stress \\
\hline $\mathrm{d}_{\mathrm{i}}$ & Internal diameter \\
\hline $\mathrm{d}_{\mathrm{o}}$ & Outer diameter \\
\hline $\mathrm{P}_{\mathrm{i}}$ & Internal pressure \\
\hline $\mathrm{T}$ & Thickness of the wall \\
\hline$\delta_{1}$ & Circumferential stress \\
\hline$\delta_{2}$ & Longitudinal Stress \\
\hline $\mathrm{P}_{1}$ & Design pressure \\
\hline$\varepsilon$ & Hoop strain \\
\hline $\mathrm{E}$ & Young modulus \\
\hline $\mathrm{L}$ & Length of Ellipsoidal head \\
\hline Dl & Displacement \\
\hline$\delta \mathrm{h}$ & Hoop stress \\
\hline $\mathrm{V}$ & Volume of the vessel \\
\hline Sall & Allowable stress \\
\hline $\mathrm{yR}$ & Partial safety yield strength \\
\hline
\end{tabular}

\section{REFERENCES}

[1] K. S. Naser, Mohammed Q, and Gupta, "Structural \& Thermal Analysis of Pressure Vessel by using Ansys," Int. J. Sci. Eng. Technol. Res., vol. 2, no. 8, pp. 740-744, 2013.

[2] I. Satyanarayana and K. Praveena, "Design And Analysis of the Pressure Vessel by using FEM," Int. J. Innov. Sci. Eng. Technol., vol. 3, no. 10, pp. 145-150, 2016.

[3] P. Sadanandam, U. Ramesh, and S. Tamerat, "Design and Analysis of Pressure Vessel Using Finite Element Method," Int. J. Latest Technol. Eng. Manag. Appl. Sci., vol. 6, no. 5, pp. 1-3, 2017.

[4] V. V Wadkar, S. S. Malgave, D. D. Patil, H. S. Bhore, and P. P. Gavade, "Design and Analysis of Pressure Vessel Using ANSYS," J. Mech. Eng. Technol., vol. 3, no. 2, pp. 1-13, 2015.

[5] V. Khobragade, Rashmi and Hiwase, "Design , And Analysis of Pressure Vessel with Hemispherical and Flat Circular End," Int. J. Eng. Sci. Comput., vol. 7, no. 5, pp. 12458-12469, 2017.

[6] A. Ibrahim, Y. Ryu, and M. Saidpour, "Stress Analysis of Thin-Walled Pressure Vessels," Mod. Mech. Eng., vol. 5, pp. 1-9, 2015.

[7] J. Z. Li, "Computer Aided Modeling and Simulation of Structural Pressure Vessel Material Computer Aided Modeling and Simulation of Structural Pressure Vessel Material Performance," in 2012 International Conference on Structures and Building Materials, 2012, pp. 1-10.

[8] O. T. Askestrand, Frode T and Gudmestad, "A Comparison Study of Pressure Vessel Design using Different Standards," in 32nd International Conference on Ocean, Offshore and Arctic Engineering (OMAE2013), June 9-14, Nantes, France, 2013, no. June, pp. 1-15.

[9] ASME, "An International Code-2010 ASME Boiler and Pressure Vessel Code Section VIII," 2010.

[10] F. Vakili-tahami, S. S. Sharifi, P. Majnoun, and A. Abbasi, "Calculating the Creep Life of Rotating Cylindrical Pressure Vessels by Reference Stress Method ( RSM )," pp. 1-18, 2015. 


\section{APPENDIX}
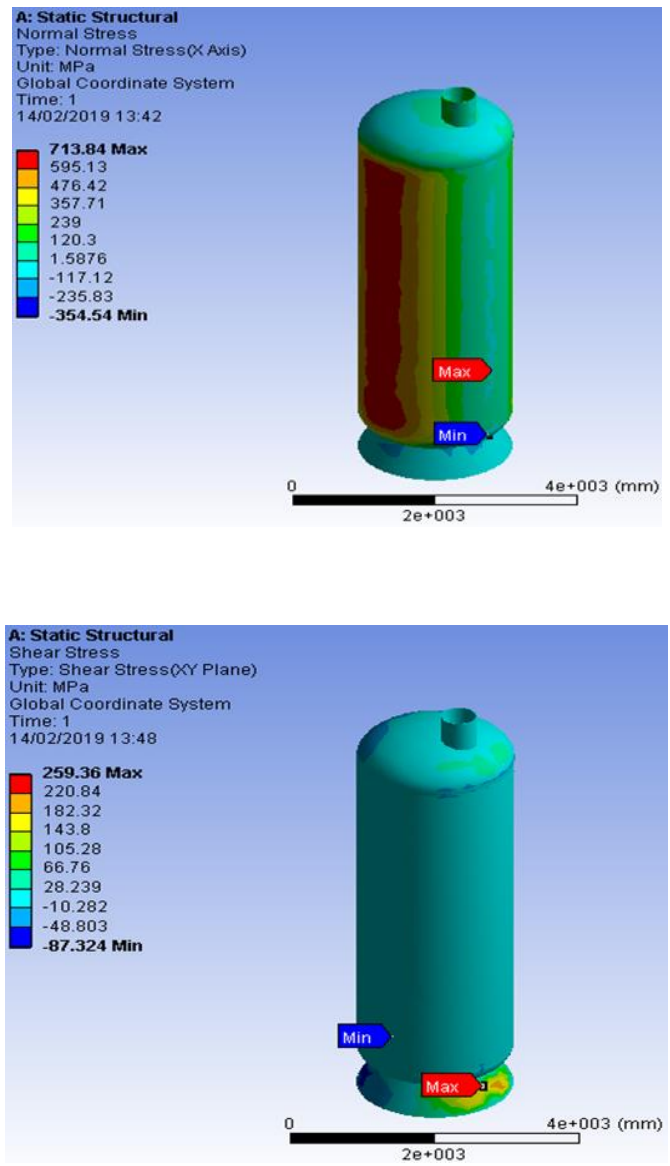

$\mathbf{k}$

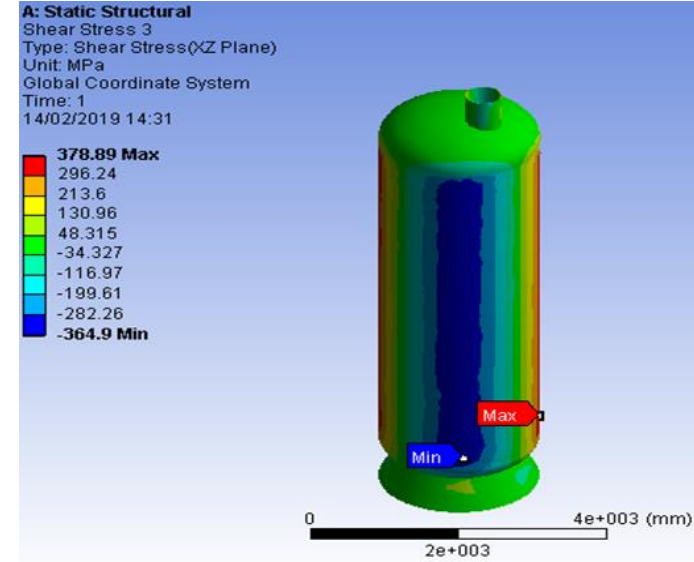

Figure A1. Rotational velocity influence on the behavior of PV at different boundary condition. h
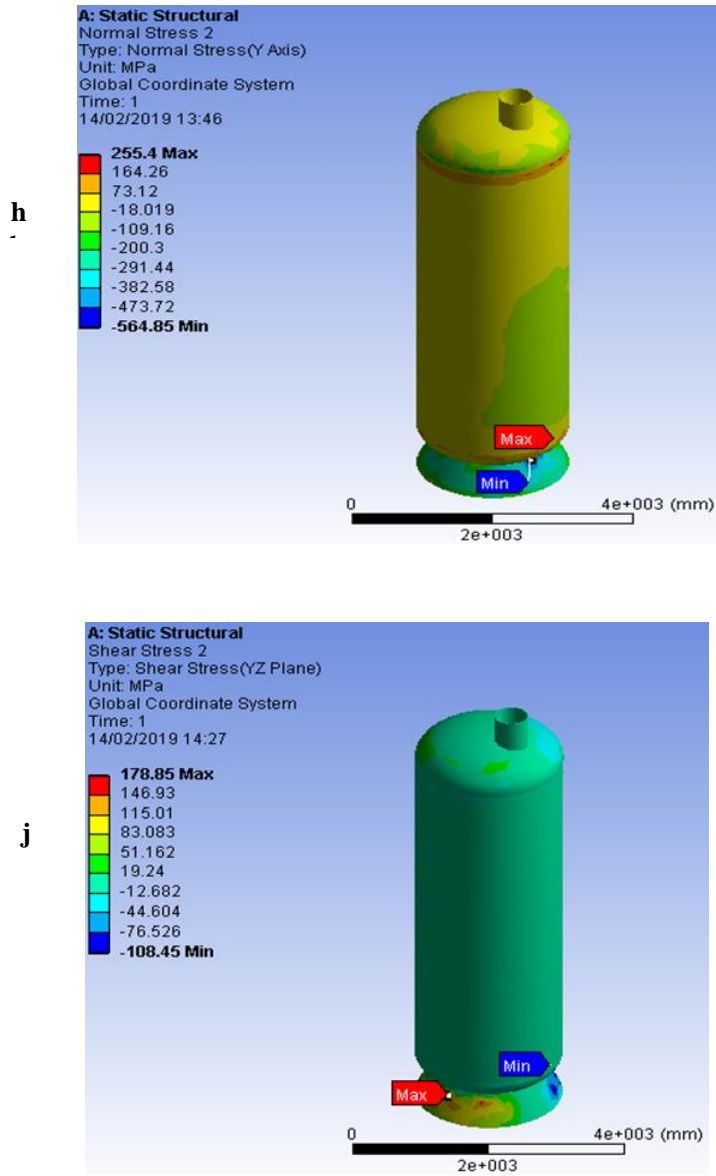